\title{
Perancangan Standard Operating Procedure (SOP)proses produksi pada TEFA (Teaching Factory) (Studi Kasus: Smk Manbaul Ulum)
}

\author{
Novi Nur Hidayanti ${ }^{1}$, Moch. Nuruddin ${ }^{2}$, hidayat ${ }^{3}$ \\ Program Studi Teknik Industri, Universitas Muhammadiyah Gresik \\ Randuagung, Kec. Kebomas, Kabupaten Gresik, Jawa Timur 61121 \\ Email: novihidayanti281099@gmail.com
}

\begin{abstract}
ABSTRAK
Perancangan SOP sangat penting dilakukan di SMK Manbaul Ulum untuk memperjelas alur kerja dalam proses produksi. Hal ini digunakan untuk menjadikan siswa lebihmemahami praktik, dan juga menjadikan siswa lebih mandiri dan siap terjun ke lingkungan kerja nantinya. SOP dalam kegiatan produksi harus diterapkan sejak dini agar siswa dapat terbiasa dengan pekerjaan yang akan mereka hadapi nanti di dalam dunia kerja. Oleh karena itu, perlu dibuat suatu standar operasi sehingga langkah-langkah dalam suatu prosedur tidak berubah. Hasil dari pembahasan pada penelitian ini yaitu:Standard Operating Prosedure (SOP) proses pemotongan Manbaul Ulum telah tersusun dengan menggunakan flowchart swimlane dan naratif, Standard Operating Prosedure (SOP) proses laminating \& edging, Standard Operating Prosedure (SOP) proses boring, Standard Operating Prosedure (SOP) proses assembling pada teaching factory di SMK Manbaul Ulum telah tersusun dengan menggunakan flowchart swimlane san naratif.
\end{abstract}

Kata Kunci: SMK, Teaching Factory, SOP

\begin{abstract}
It is very important to design SOPs in Manbaul Ulum Vocational School to clarify the workflow in the production process. This is used to make students better understand the practice, and also to make students more independent and ready to enter the work environment later. SOPs in production activities must be applied from an early age so that students can get used to the work they will face later in the world of work. Therefore, it is necessary to create an operating standard so that the steps in a procedure do not change. The results of the discussion in this study are: Standard Operating Procedure (SOP) for the Manbaul Ulum cutting process has been arranged using a swimlane and narrative flowchart, Standard Operating Procedure (SOP) for laminating \& edging process, Standard Operating Procedure (SOP) for boring process, Standard Operating Procedure (SOP) assembling process at the teaching factory at SMK Manbaul Ulum has been arranged using a flowchart swimlane san narrative.
\end{abstract}

Keywords: SMK, Teaching Factory, SOP

\section{Jejak Artikel}

Upload artikel : 15 Desember 2021

Revisi : 25 Desember 2021

Publish : : 31 Januari 2022 


\section{Pendahuluan}

Menurut Sri Handayani (2019), pendidikan merupakan salah satu faktor penting dalam pembangunan bangsa indonesia. Pendidikan menengah kejuruan atau SMK adalah pendidikan jenjang menengah yang mengutamakan pengembangan kemampuan siswa untuk melaksanakan jenis pekerjaan tertentu (Nisa Surya Pertiwi, 2019). Pendidikan menengah kejuruan mengutamakan penyiapan siswa untuk memasuki lapangan kerja serta mengembangkan sikap profesional (Peraturan Pemerintah Nomor 29 Tahun 1990). Lulusan SMK disiapkan untuk memiliki kompetensi agar dapat bersaing dalam dunia kerja atau mampu berwirausaha, salah satunya yaitu dengan adanya suatu Teaching Factory sebagai tempat bagi siswa untuk melaksanakan kegiatan pembelajaran praktik yang dirancang sehingga menyerupai lingkungan kerja.

Teaching Factory merupakan suatu konsep pembelajaran di SMK berbasis produksi yang mengacu kepada standar dan prosedur yang berlaku di industri dan dilaksanakan dalam suasana seperti yang terjadi di industri. Menurut Nur Ayu Dwilestari (2019), ada 6 karakteristik pendidikan kejuruan, yaitu mempersiapkan peserta didik memasuki lapangan kerja, di dasarkan kebutuhan dunia kerja, penguasaan kompentensi yang dibutuhkan dunia kerja, kesuksesan peserta didik pada performa dunia kerja, hubungan erat dengan dunia kerja, responsive dan antisipatif terhadap kemajuan teknologi.

Dalam konsep sederhana teaching factory merupakan pengembangan dari pendidikan sistem ganda, yaitu Competence Based Training (CBT) dan Production Based Education and Training (PBET) yang dilaksanakan oleh SMK. Sebelumnya SMK masih kesulitan untuk menerapkan pendidikan berbasis produksi. Oleh karena itu dimunculkan istilah teaching factory yang mengharuskan sekolah SMK memiliki tempat untuk siswa melaksanakan pembelajaran praktik yang dirancang sedemikian rupa sehingga menyerupai lingkungan kerja. Pada suatu proses produksi dibutuhkan sebuah pedoman agar proses produksi berjalan efektif. Standard Operating Prosedure (SOP) pada dasarnya adalah pedoman yang berisi prosedur-prosedur operasional standar yang ada di dalam suatu organisasi yang digunakan untuk memastikan bahwa semua keputusan dan tindakan, serta penggunaan fasilitasfasilitas proses yang dilakukan di dalam organisasi agar berjalan efektif dan efisien, konsisten, standar dan sistematis (Nisa Surya Pertiwi, 2019). SOP dalam suatu produksi sangat dibutuhkan untuk membantu menghasilkan sebuah produk yang bermutu. Dalam SOP juga harus mencakup prosedur yang dapat meningkatkan keahlian dari peserta didik.

Dari hasil observasi dan wawancara saat ini SMK Manbaul Ulum menerapkan model pembelajaran Teaching Factory 6M, yaitu menerima pemberian order, menganalisis order, menyatakan kesiapan mengerjakan order, mengerjakan order, melakukan quality control, dan menyerahkan order. Namun peserta didik belum terlibat dalam seluruh tahapan model TF-6M, hanya pada tahapan mengerjakan order saja, tahapan lainnya masih dilakukan oleh guru. Dalam kegiatan produksi sendiri juga masih belum memiliki SOP, sehingga produk yang dibuat di SMK Manbaul Ulum masih belum memiliki konsistensi produk yang tetap yaitu mutu produk yang belum seragam. Menurut Nisa Surya Pertiwi (2019), produk yang tidak konsisten sebagian besar disebabkan oleh variasi standar dan mutu yang kurang baik. Artinya belum adanya suatu 
ketetapan dalam pembuatan suatu produk sehingga memiliki beragam variasi standar dan mutu. Para siswa yang terlibat dalam proses produksi masih belum memahami tugas dan alur kerja produk yang akan mereka buat, menyebabkan kemungkinan terjadi kesalahan dapat terjadi. Selain hal tersebut, proses produksi yang dilakukan oleh siswa hanya berdasarkan pengalaman dan instruksi dari guru, sehingga siswa belum mandiri dalam melakukan produksi, padahal ketika lulus siswa diharapkan siap untuk dapat bersaing dalam dunia kerja.

Perancangan SOP sangat penting dilakukan di SMK Manbaul Ulum untuk memperjelas alur kerja dalam proses produksi. Hal ini digunakan untuk menjadikan siswa lebih memahami praktik, dan juga menjadikan siswa lebih mandiri dan siap terjun ke lingkungan kerja nantinya. SOP dalam kegiatan produksi harus diterapkan sejak dini agar siswa dapat terbiasa dengan pekerjaan yang akan mereka hadapi nanti di dalam dunia kerja. Oleh karena itu, perlu dibuat suatu standar operasi sehingga langkah-langkah dalam suatu prosedur tidak berubah. Dengan adanya SOP diharapkan dapat meminimalisir kesalahan kerja dan menghasilkan produk dengan kualitas yang konsisten, serta peserta didik dapat memiliki kompetensi yang sesuai dengan Standar Kompetensi Kerja Nasional Indonesia (SKKNI) dalam melaksanakan tugas.

\section{Metodologi Penelitian}

\subsection{Rancangan Penelitian}

Penelitian yang dilakukan adalah penelitian kualitatif. Penelitian kualitatif merupakan proses eksplorasi dan memahami makna perilaku individu dan kelompok, menggambarkan masalah sosial atau masalah kemanusiaan (Rusda Irawati \& Enstien Basuki Woro Hardiastuti, 2016). Penelitian ini dimulai dengan melakukan observasi di sekolah. Pada tahap ini, peneliti melakukan observasi dan wawancara mengenai teaching factory, meliputi proses pemotongan, proses laminating \& edging, proses boring, dan proses assembling.

Selanjutnya identifikasi proses pemotongan, proses laminating \& edging, proses boring, dan proses assembling pada teaching factory yang dapat diangkat sebagai suatu kasus untuk penelitian. Setelah mendapat daftar permasalahan, kemudian menentukan fokus penelitian pada permasalahan atau kasus yang kemudian dibahas dalam penelitian ini.

Tahap penelitian menggunakan tiga metode pengambilan data yaitu wawancara, dokumentasi dan observasi. Tahap beikutnya adalah melakukan perancangan SOP. Selanjutnya pengajuan rancangan SOP ke pihak sekolah. Kemudian apabila disetujui maka SOP dapat digunakan, namun apabila tidak disetujui maka SOP tersebut harus dilakukan revisi. Tahap terakhir yaitu hasil rancangan dan kesimpulan untuk rekomendasi yang dapat diajukan kepada sekolah dari hasil penelitian.

\section{Pembahasan}

\subsection{Standard Operating Prosedure (SOP)}

Standard Operating Prosedure (SOP) merupakan dokumen yang lebih jelas dan rinci untuk menjabarkan metode yang digunakan dalam mengimplementasikan dan melaksanakan kebijakan dan aktivitas organisasi seperti yang ditetapkan dalam pedoman. Pada dasarnya, prosedur merupakan instruksi tertulis sebagai pedoman dalam menyelesaikan sebuah tugas rutin atau tugas yangberulang dengan cara yang efektif dan efisien, untuk menghindari terjadinya variasi atau penyimpangan yang dapat mempengaruhi kinerja perusahaan secarakeseluruhan (Rusda Irawati \& Enstien Basuki W H, 2016). Rancangan Standard Operating Prosedure (SOP) yang akan digunakan pada proses pemotongan, proseslaminating \& edging, 
proses boring, dan proses assembling pada teaching factory di SMK Manbaul Ulumdengan metode Cross Functional Flowchar yang digabungkan dengan narasi. Rancangan yang dibuat dapat dilihat seperti berikut:

\section{a. Proses Pemotongan}

Proses pemotongan merupakan aktivitas dalam proses produksi yang utama dan memiliki peranan penting dalam teaching factory di SMK Manbaul Ulum. Proses pemotongan selama ini ditemui beberapa masalah, karena proses pemotongan belum dilakukan dengan baik. Sehingga dalam proses pemotongan dilengkapi dengan intruksi kerja. Setelah melakukan wawancara dan observasi didapatkanlah Standard Operating Prosedure (SOP) proses pemotongan seperti dibawah ini:

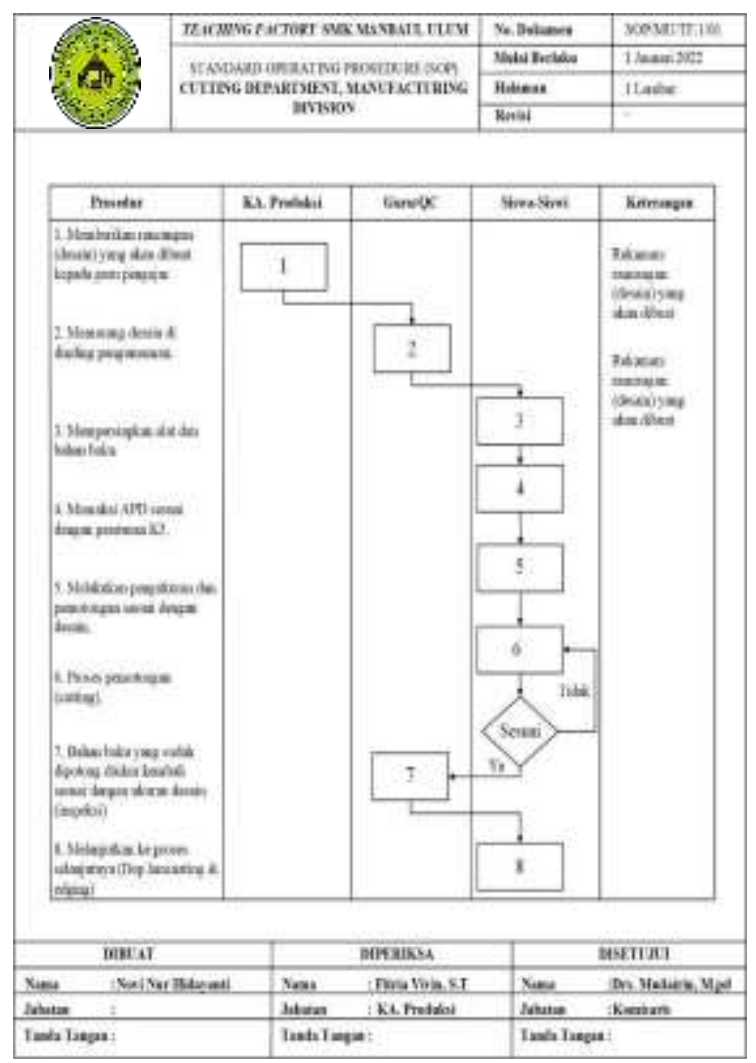

Gambar 3.1 Standard Operating Prosedure (SOP)

Proses Pemotongan

b. Proses Laminating \& Edging

Proses laminating \& edging merupakan aktivitas ke duasetelah proses pemotongan dalam proses produksi di teaching factory. Prosedur ini berkaitan dengan intruksi kerja pada proses laminating \& edging. Standard

Operating Prosedure (SOP) proses

laminating \& edgingdapat dilihat seperti dibawah ini:

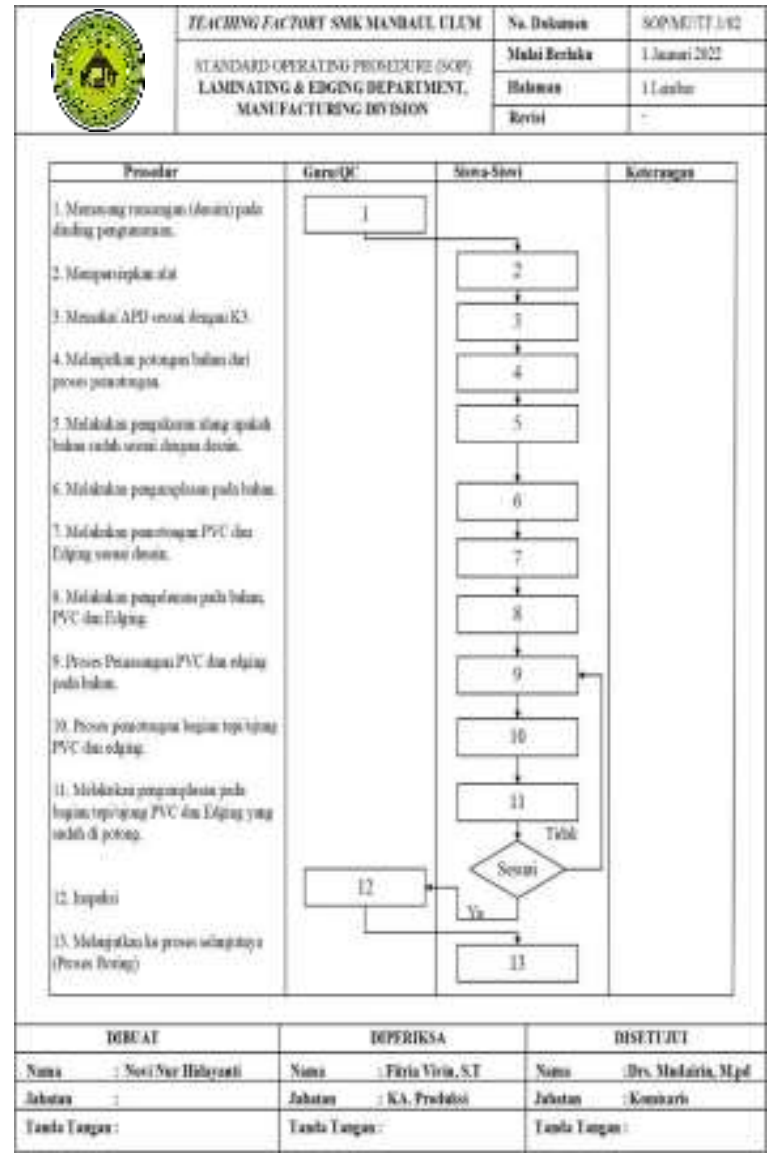

Gambar 3.2 Standard Operating Prosedure (SOP) Proses Laminating \& Edging

\section{c. Proses Boring}

Proses boring merupakan aktivitas ke tiga setelah proses laminating \& edging dalam proses produksi di teaching factory. Prosedur ini berkaitan dengan intruksi kerja pada proses boring. Setelah melakukan wawancara dan observasi didapatkanlah Standard Operating Prosedure (SOP) proses boring seperti dibawah ini: 


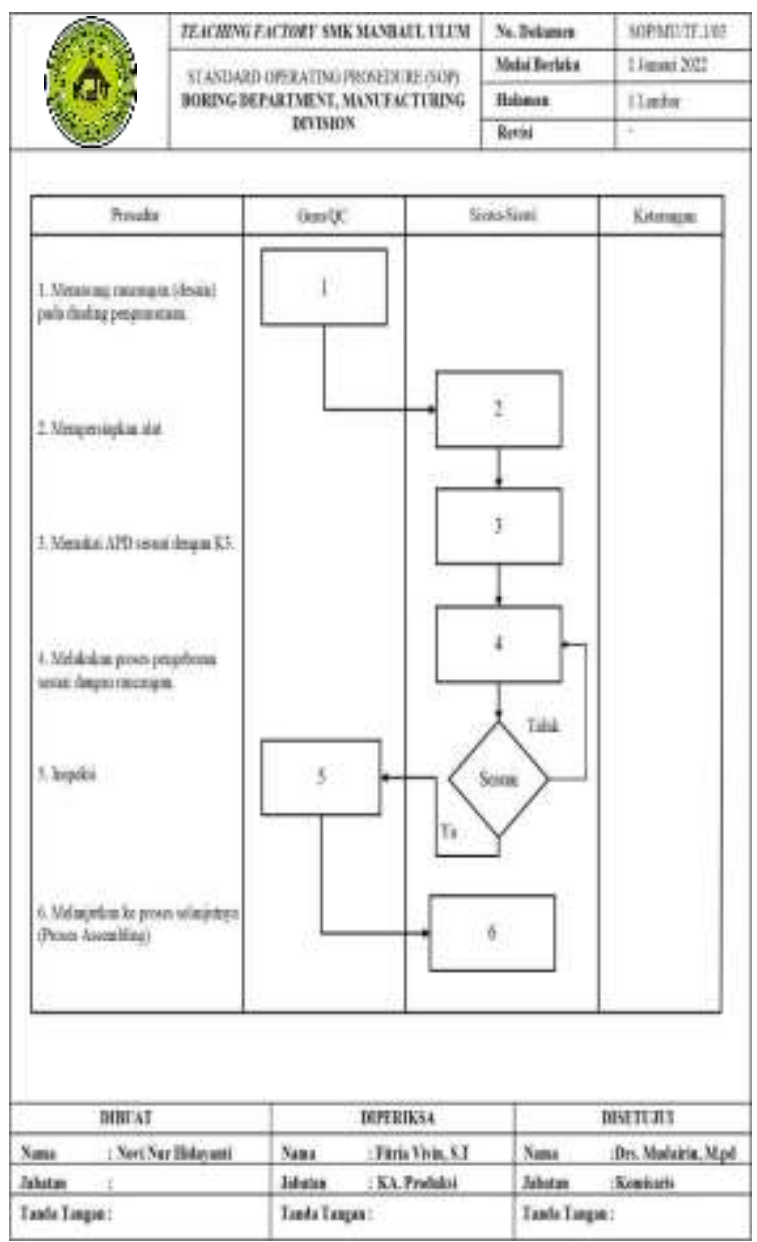

Gambar 3.3 Standard Operating Prosedure (SOP) Proses Boring

d. Proses Assembling

Proses assembling merupakan aktivitas terakhir setelah proses pemotongan dalam proses produksi di teaching factory. Proses assembling sendiri tidak ditemui masalah, karena proses assembling sudah dilakukan dengan baik. Sehingga dalam proses assembling tidak dilengkapi dengan instruksi kerja. Standard Operating Prosedure (SOP) proses assembling dapat dilihat seperti dibawah ini:

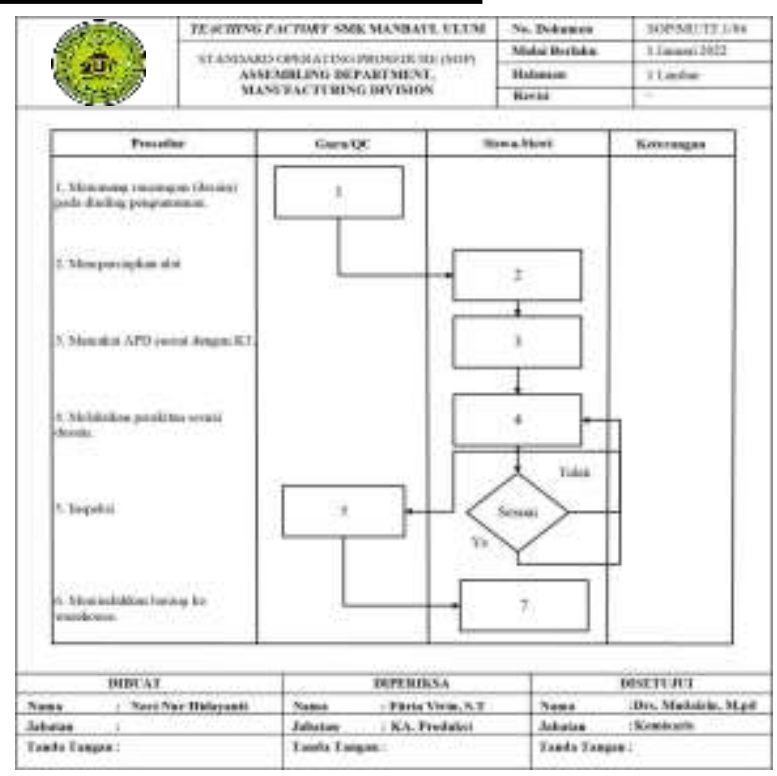

Gambar 3.4 Standard Operating Prosedure (SOP)Proses Assembling

\section{Kesimpulan}

Hasil dari pembahasan pada penelitian ini yaitu:

1. Standard Operating Prosedure (SOP) proses pemotongan pada teaching factory di SMK Manbaul Ulum telah tersusun dengan menggunakan flowchart swimlane san naratif.

2. Standard Operating Prosedure (SOP) proses laminating \& edging pada teaching factory di SMK Manbaul Ulum telah tersusun dengan menggunakan flowchart swimlane san naratif.

3. Standard Operating Prosedure (SOP) proses boring pada teaching factory di SMK Manbaul Ulum telah tersusun dengan menggunakan flowchart swimlane sannaratif.

4. Standard Operating Prosedure (SOP) proses assembling pada teaching factory di SMK Manbaul Ulum telah tersusun dengan menggunakan flowchart swimlane san naratif.

\section{DAFTAR PUSTAKA}

Handayani, Sri. 2019. Pembuatan Standart Operasional Prosedur (SOP)

Praktikum Fisika Untuk Meningkatkan Efisiensi Pelasanaan Praktikum Fisika Sma. Jurusan Pendidikan MIPA.

Gozal, Satrio. 2017. Perancangan Standar 
Operasional Prosedur siklus Operasional

Pada Perusahaan Stagger Media. Universitas Ciputra.

Irawati, Rusda. 2016. Perancangan Standard Operating Procedure (SOP) Proses Pembelian Bahan Baku, Proses Produksi dan Pengemasan pada Industri Jasa Boga. Politeknik Negri Batam. Jurnal Akutansi, Ekonomi dan Manajemen Bisnis Vol 4, No 2.

Dwilestari, Nur Ayu. 2019. Pengembangan Standart Operating Prosedure (SOP) Teaching Factory Produk Kopi Arabika Berbasis SKKNI di SMP PPN Lembang. Universitas Pendidikan Indonesia.

Pertiwi, Nisa Surya. 2019. Pengembangan Standart Operating Procedure (SOP) Proses Produksi Roti Berbasis SKKNI di Teaching Factory SMK Negeri 1 Cibadak.

Setiawati, wiwien. 2015. Penyusunan Standart Operating Procedures (SOP) pada PT Sketsa Cipta Graha di Surabaya. Universitas Kristen Petra. 